\title{
Tight correlation between expression of the Forkhead transcription factor FOXMI and HER2 in human breast cancer Nuran Bektas ${ }^{1}$, Anette ten Haaf ${ }^{1}$, Jürgen Veeck ${ }^{1}$, Peter Johannes Wild ${ }^{2}$, Juliane Lüscher-Firzlaff ${ }^{3}$, Arndt Hartmannn ${ }^{4}$, Ruth Knüchel ${ }^{1}$ and Edgar Dahl*1
}

Address: ${ }^{1}$ Institute of Pathology, University Hospital of the RWTH Aachen, Aachen, Germany, ${ }^{2}$ Institute of Pathology, University Hospital Zürich, Zürich, Switzerland, ${ }^{3}$ Institute of Biochemistry, University Hospital of the RWTH Aachen, Aachen, Germany and ${ }^{4}$ Department of Pathology, University of Erlangen, Erlangen, Germany

Email: Nuran Bektas - nbektas@ukaachen.de; Anette ten Haaf - atenhaaf@ukaachen.de; Jürgen Veeck - juergen.veeck@rwth-aachen.de; Peter Johannes Wild - peter.wild@usz.ch; Juliane Lüscher-Firzlaff - jluescher-firzlaff@ukaachen.de; Arndt Hartmann - arndt.hartmann@klinik.uni-regensburg.de; Ruth Knüchel -rknuechel-clarke@ukaachen.de; Edgar Dahl* - edahl@ukaachen.de

* Corresponding author

Published: 6 February 2008

BMC Cancer 2008, 8:42 doi:10.1 | 86/147|-2407-8-42
Received: 23 October 2007

Accepted: 6 February 2008

This article is available from: http://www.biomedcentral.com/I47I-2407/8/42

(C) 2008 Bektas et al; licensee BioMed Central Ltd.

This is an Open Access article distributed under the terms of the Creative Commons Attribution License (http://creativecommons.org/licenses/by/2.0), which permits unrestricted use, distribution, and reproduction in any medium, provided the original work is properly cited.

\begin{abstract}
Background: FOXMI regulates expression of cell cycle related genes that are essential for progression into DNA replication and mitosis. Consistent with its role in proliferation, elevated expression of FOXMI has been reported in a variety of human tumour entities. FOXMI is a gene of interest because recently chemical inhibitors of FOXMI were described to limit proliferation and induce apoptosis in cancer cells in vitro, indicating that FOXMI inhibitors could represent useful anticancer therapeutics.
\end{abstract}

Methods: Using immunohistochemistry (IHC) we systematically analysed FOXMI expression in human invasive breast carcinomas $(n=204)$ and normal breast tissues $(n=46)$ on a tissue microarray. Additionally, using semiquantitative realtime PCR, a collection of paraffin embedded normal $(n=12)$ and cancerous $(n=25)$ breast tissue specimens as well as benign $(n=3)$ and malignant mammary cell lines $(n=8)$ were investigated for FOXMI expression. SPSS version I4.0 was used for statistical analysis.

Results: FOXMI was found to be overexpressed in breast cancer in comparison to normal breast tissue both on the RNA and protein level (e.g. 8.7 fold as measured by realtime PCR). We found a significant correlation between FOXMI expression and the HER2 status determined by HER2 immunohistochemistry $(P<0.05)$. Univariate survival analysis showed a tendency between FOXMI protein expression and unfavourable prognosis $(P=0.110)$.

Conclusion: FOXMI may represent a novel breast tumour marker with prognostic significance that could be included into multi-marker panels for breast cancer. Interestingly, we found a positive correlation between FOXMI expression and HER2 status, pointing to a potential role of FOXMI as a new drug target in HER2 resistant breast tumour, as FOXMI inhibitors for cancer treatment were described recently. Further studies are underway to analyse the potential interaction between FOXMI and HER2, especially whether FOXMI directly activates the HER2 promoter. 


\section{Background}

Fox (Forkhead Box) proteins, characterised by a 100 amino acid winged-helix DNA binding domain, are chordate transcription factors that play important roles in the regulation of growth and development [1,2]. FOXM1 is ubiquitously expressed in cells undergoing proliferation $[3,4]$. It is required for normal coupling of DNA replication (at $S$ phase) and chromosomal segregation (at $M$ phase) during cell cycle progression [5]. FOXM1 expression peaks at G2/M-transition and is believed to exert its S-M coupling role by promoting $M$ phase entry and suppressing DNA re-replication [6].

FOXM1 is localised mainly in the cytoplasm during late G1 and S phases, but is found to be phosphorylated and translocated to the nucleus before cells entry into the G2/ $\mathrm{M}$ phase. Activation of the Raf/MEK/MAPK pathway is necessary for the nuclear translocation of FOXM1 protein [6]. Consistent with its role in promoting proliferation, elevated expression of FOXM1 has recently been reported in a variety of human tumour entities including breast [7] and liver cancer [8]. FOXM1 depletion causes a certain form of cell death - so called mitotic catastrophe - that occurs during mitosis often arising from aberrant G2 checkpoint control [9]. Therefore inhibition of FOXM1 expression could represent a new target in the therapeutic treatment of breast cancer [9].

Very recently, in vitro data have demonstrated a direct regulation of the oestrogen receptor gene (ESR1) by FOXM1 protein binding to the ESR1 promoter, thus leading to upregulation of oestrogen receptor-alpha (ER $\alpha)$ expression at mRNA transcript and protein levels [10]. It is well known that oestrogen receptors play a major role in the regulation of growth, survival and differentiation of normal and malignant breast epithelial cells $[11,12]$. Therefore the determination of breast tumour hormone receptor status is of major importance for therapy selection [13]. Approximately $60-80 \%$ of all breast cancers abundantly express ER $\alpha$, but only two thirds of those patients are responsive to endocrinal treatment (anti-oestrogen therapy). Intriguingly, a proportion of ER $\alpha$-positive tumours do not respond to hormone treatment at all (de novo resistance) whilst the majority of those tumours that initially responded to anti-oestrogens eventually become resistant during treatment (acquired resistance). Most ER-resistant tumours remain ER $\alpha$-positive, suggesting a continued role for ER $\alpha$ in breast cancer cell survival and proliferation $[14,15]$. The very likely development of ER-resistance during breast cancer treatment with antioestrogens, like the resistances described for treatment with the HER2 antibody Herceptin ${ }^{\circledR}$, emphasises that there is an urgent need for surrogate target molecules that may allow bypassing these resistances. Recently, numerous candidate genes which are highly differentially expressed in breast cancer have been identified by our research group $[16,17]$. FOXM1 is one of these candidate genes and has been selected for further analysis because chemical inhibitors of this target molecule are already available and have been shown to limit proliferation e.g. in liver cancer cells in vivo $[18,19]$. Thus FOXM1 inhibitors could represent useful new anticancer therapeutics for breast cancer as well. So far little is known about the expression of FOXM1 in normal and cancerous human breast tissue. In the present study we systematically analysed the expression of FOXM1 in human breast carcinomas and normal breast tissue on both the mRNA and protein level and analysed the results especially in correlation to hormone receptor status, HER2 status and patient survival data.

\section{Methods Patient samples on the breast cancer tissue microarray (TMA)}

FOXM1 protein expression in breast cancer patients was assessed using a TMA that has been previously described [17] and that consisted of 204 breast cancer specimens and 46 normal breast tissue specimens. The TMA contained one tissue core from non-selected, formalin-fixed and paraffin-embedded primary breast cancer specimens diagnosed between 1994 and 2002 at the Institute of Pathology, University of Regensburg, Germany. Patients' age ranged from 25 to 82 years with a median age of 56 years. An experienced surgical pathologist (A.H.) evaluated H\&E-stained slides of all specimens prior to construction of the TMA in order to identify representative tumour areas. Histologically, all tumours were graded according to Elston and Ellis [20]. Clinical follow-up data, provided by the Central Tumour Registry, Regensburg, Germany were available for all 204 breast cancer patients with a median follow-up period of 78 months (range 0-148 months). All patients gave informed consent for retention and analysis of their tissue for research purposes and the Institutional Review Board of the participating centre approved the study. The paraffin-embedded and formalin-fixed normal $(n=14)$ and cancerous $(n=25)$ breast tissue samples for mRNA expression analysis have been described previously [21].

\section{Cell lines}

The human mammary epithelial cell lines HMEC, MCF10A and MCF12A as well as the breast cancerous cell lines MCF7, T47D, ZR75-1, MDA-MB231, MDA-MB468, MDA-MB435s, SKBR3 and BT20 were obtained from the ATCC (Rockville, MD, USA) and cultured as previously described [22].

\section{RNA extraction and reverse transcription}

Total RNA was isolated by use of TRIzol reagent (Invitrogen, Carlsbad, CA, USA) according to the manufacturers' 
recommendations. For paraffin-embedded tissues, sufficient sections were prepared, deparaffinised and conventionally re-hydrated in a decreasing alcohol-series prior to RNA extraction. Of the obtained RNA, one $\mu \mathrm{g}$ was reverse transcribed using the Reverse Transcription System (Promega, Madison, WI, USA). In order to improve transcription rate we mixed oligo-dT and $\mathrm{pdN}_{6}$ primers 1:2.

\section{Semiquantitative realtime $P C R$}

Semiquantitative PCR was performed using the LightCycler system together with the LightCycler DNA Master SYBR Green I Kit (Roche Diagnostics, Mannheim, Germany) as described elsewhere [22]. To ensure experiment accuracy, all reactions were performed in triplicate. Primer sequences were: FOXM1 sense 5'-GAG CAC TTG GAA TCA CAG CA-3' and antisense 5'-CAC CGG GAA CTG GAT AGG TA-3'; GAPDH sense 5'-GAA GGT GAA GGT CGG AGT CA-3' and antisense 5'-AAT GAA GGG CTC ATT GAT GG-3'. Annealing temperatures for both genes were set to $60^{\circ} \mathrm{C}$. Reaction specificity was controlled by post-amplificational melting curve analyses as well as by gel electrophoresis of the obtained products.

\section{Immunohistochemical characterisation of the tissue microarray}

Immunohistochemical (IHC) studies for the expression of HER2 utilised an avidin-biotin peroxidase method with a 3,3'-diaminobenzidine (DAB) chromatogen. After antigen retrieval (microwave oven for $30 \mathrm{~min}$ ) IHC was carried out in a NEXES immunostainer (Ventana, Tucson, AZ, USA) following the manufacturer's instructions. The following primary antibodies were used: anti-HER2 (DAKO, Hamburg, Germany; 1:400), anti-ER and anti-PR (Novocastra, Newcastle Upon Tyne, UK; 1:20). For target proteins the ChemMate detection kit (DAKO) was used. A surgical pathologist (A.H.) performed a blinded evaluation of the TMA slides without knowledge of clinical data. Causes of non-interpretable results included lack of tumour tissue and presence of necrosis or crush artefacts. HER2 expression was scored according to the DAKO HercepTest. For the evaluation of ER and PR presence, a semiquantitative immunoreactivity score (IRS), as described by Remmele and Stegner [23], was used.

\section{FOXMI Immunohistochemistry}

The tissue microarray was subjected to immunostaining using the Advance Kit (DAKO K4068) following the manufacturer's instructions. Breast carcinomas were used as positive controls. After deparaffinisation and re-hydration the tissue samples were boiled in a microwave oven for 30

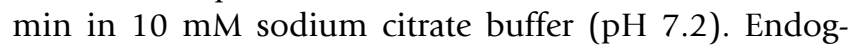
enous peroxidase was blocked by Peroxidase blocking solution (DAKO S 2023). The polyclonal primary antibody FOXM1 (Santa Cruz sc502) was applied (1:30) for 1 $\mathrm{h}$ at room temperature. In negative controls the primary antibody was omitted. The Advance Kit HRP against rab- bit/mouse (DakoCytomation K 4065, Carpintera, CA, USA) was applied to signal amplification for $30 \mathrm{~min}$. For signal detection 3,3'-diaminobenzidine (DAB) was used. Slides were counterstained with hematoxylin and after dehydration mounted in Vitro-Clud (Langenbrinck, Emmendingen, Germany). An experienced pathologist (N.B.) scored the immunohistochemical staining intensity according to the scoring system suggested by Remmele and Stegner [23].

\section{Statistical analysis}

For statistical evaluation the SPSS software version 14.0 (SPSS GmbH Software, Munich, Germany) was used. Differences were considered statistically significant when pvalues were $<0.05$. A non-parametrically two-tailed Mann-Whitney $U$-test was employed to analyse differences in expression levels. A statistical association between clinicopathological and molecular parameters was tested, using two-sided Fisher's exact test. Recurrencefree (RFS) and overall survival (OS) were calculated according to the Kaplan-Meier equation.

\section{Results \\ Upregulation of FOXMI in cancerous human epithelial breast cell lines}

We initiated our study by investigating the level of FOXM1 mRNA expression in non-malignant and malignant human mammary cell lines. Realtime PCR analysis revealed a homogenous FOXM1 mRNA expression in non-malignant mammary epithelial cell lines such as HMEC, MCF10A and MCF12A, whereas FOXM1 mRNA transcript levels were more heterogeneous and in total elevated in cancerous cell lines (Figure 1). The metastatic breast cancer cell line MDA-MB231 presented an exceptionally high level of FOXM1 expression (Fig. 1). The difference in FOXM1 expression between normal and cancerous breast cell lines was statistically significant $(P=$ 0.048, Mann-Whitney $U$-test).

\section{Upregulation of FOXMI in primary breast cancers}

Next we analysed FOXM1 mRNA expression by realtime PCR in primary human breast cancers $(\mathrm{n}=25)$ and normal mammary samples $(n=12)$ derived from formalinfixed, paraffin-embedded tissues. In line with the expression data in breast cell lines, FOXM1 mRNA was strongly upregulated in primary breast cancer specimens compared to normal mammary epithelial tissue (Fig. 2). The median fold change of FOXM1 upregulation in the cancerous tissue versus normal was 8.7 and difference in expression between the two groups was statistically significant $(P=0.029$, Mann-Whitney $U$-test $)$.

\section{FOXMI protein expression in primary human breast} cancer

By use of a large tissue microarray $(\mathrm{n}=250)$ we investigated the protein expression of FOXM1 in breast cancer 


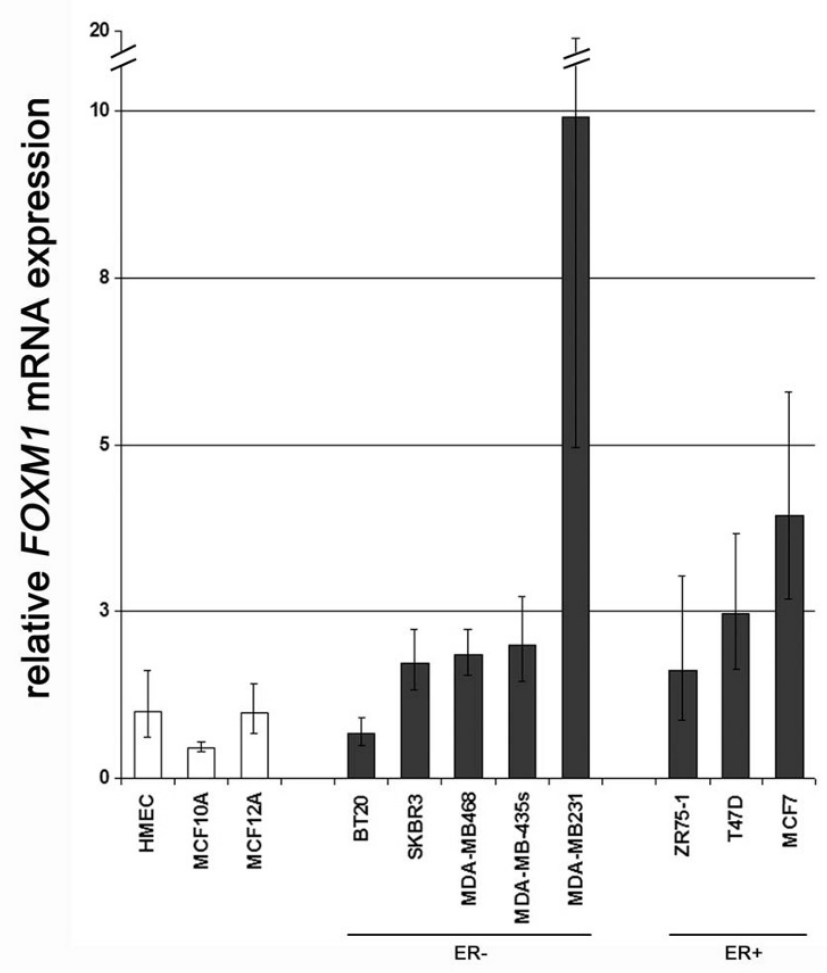

Figure I

Elevated expression of FOXMI mRNA in breast cancer cell lines. Semiquantitative realtime PCR (LightCycler) of FOXMI expression was performed on reverse transcribed RNA from non-malignant (white bars) and malignant cell lines (black bars). A significant difference in expression between both groups was detected $(P=0.048)$, whereas classification of malignant breast cell lines into oestrogen receptor (ER) positive and negative revealed no significant coherence with FOXMI expression ( $P=0.655$; two-tailed Mann-Whitney $U$ test).

specimens and normal breast tissues. FOXM1 is expressed in the nucleus as well as in the cytoplasm of benign and malignant mammary gland epithelial cells. Expression was absent in the fibrolipomatous stroma and in vessels. In normal breast tissue FOXM1 expression was often absent or weaker in the nucleus compared with breast carcinomas. In Figure 3(A, B) normal breast tissue is shown with very weak FOXM1 expression in the nucleus (IRS =1) and weak FOXM1 expression in the cytoplasm (IRS = 4). In ductal carcinoma in situ of high grade type (Figure 3, C and 3D) nuclear FOXM1 expression is slightly more intense (IRS = 2) than in normal breast tissue whereas the cytoplasmic FOXM1 expression is strong (IRS = 9). In invasive breast carcinomas (Figure 3, E and 3F, ductal type) FOXM1 expression was often abundant in the nucleus (IRS = 3) as well as in the cytoplasm (IRS = 12) compared with normal breast tissue and ductal carcinoma in situ. In tubular breast carcinomas (Figure 3, G and 3H), a less frequent variant of invasive breast carcinomas with a more favourable prognosis than invasive ductal breast carcinomas, nuclear and cytoplasmic FOXM1 expression (each IRS = 3) was weaker than in most invasive ductal breast carcinomas and stronger than in most normal breast tissues. Considering the whole tissue microarray $87 \%(187 / 204)$ of the breast carcinomas expressed nuclear FOXM1 versus 42\% (19/46) of normal breast tissue specimens. In accordance with this number the median nuclear immunoreactive score in breast carcinomas (median IRS $=3$ ) was higher than in normal breast tissue (median IRS $=0$ ).

\section{Correlation between nuclear FOXMI and clinicopathological patient parameters}

For statistical analysis only nuclear FOXM1 expression was considered because FOXM1 is known to be a transcriptional factor exercising its biological effect especially in the nucleus. Nuclear FOXM1 protein with an IRS $\geq 2$ was considered as positive FOXM1 expression while IRS = 0 and IRS = 1 were considered as negative FOXM1 expression. Nuclear FOXM1 expression was not associated with tumour stage, lymph node status, histological grading, focality or histological type of tumour (Table 1). Nuclear FOXM1 was associated with the presence of oestrogen receptor with marginal significance $(P=0.085)$ but not with presence of progesterone receptor $(P=0.702)$. Importantly, a significant association was detected between nuclear FOXM1 and high expression of the HER2 receptor as determined by immunohistochemistry (DAKO score $3+; P=0.045$ ) (Table 1 ).

To investigate an impact of FOXM1 overexpression on patients' clinical outcome we calculated univariate survival probability curves with respect to immunohistochemical results. We found that nuclear FOXM1 expression in breast cancer (IRS $\geq 2$ ) shows a tendency towards unfavourable prognosis regarding overall survival as shown by Kaplan-Meier analysis $(P=0.110)$ (Table 2, Figure 4). However, recurrence-free survival was not significantly associated with FOXM1 overexpression (Table 2).

\section{Discussion}

Fox (Forkhead box) proteins are chordate transcription factors with an important role for cellular events such as regulation of cell growth and cellular development [1-3]. In accordance with the observed role of FOXM1 in cell cycle progression and cell proliferation, elevated expression of FOXM1 has been reported in several human tumour entities $[7,8]$. Recently, FOXM1 expression has been analysed in human breast carcinomas, showing that mRNA transcript levels of the FOXM1 gene were upregulated in tumour tissue as compared to normal breast tissue [7]. However, this study neither analysed FOXM1 protein 


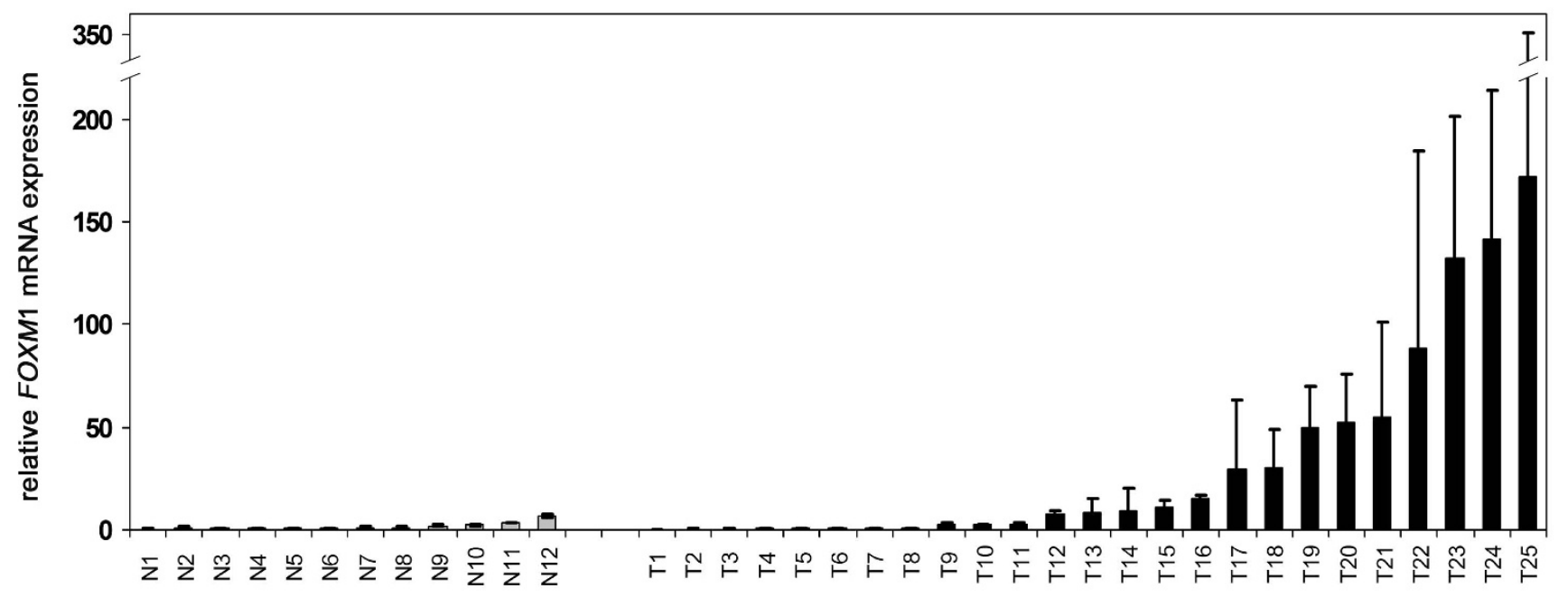

\section{Figure 2}

Upregulation of FOXMI expression in primary breast cancer. A collection of paraffin-embedded breast carcinomas $(\mathrm{T} ; \mathrm{n}=25)$ and normal breast tissues $(\mathrm{N} ; \mathrm{n}=\mathrm{I}$ ) was analysed for FOXMI expression by semiquantitative realtime PCR. In total, we detected a strong upregulation at transcript level in the tumourous tissues as compared with normal breast tissues.

expression in breast tumour tissues nor did it evaluate the impact of FOXM1 deregulation on patient prognosis. On a large cohort of breast cancer specimens we performed a first systematic expression analysis of FOXM1 on both mRNA and protein level and subsequently studied FOXM1 expression with respect to clinicopathological parameters and patients' survival data.

In concordance with the data from Wonsey et al. [7] upregulation of FOXM1 mRNA was found in paraffinembedded breast carcinomas compared to normal breast tissue. Consistent with FOXM1 overexpression in human breast tumours, malignant mammary cell lines such as MCF7, MDA-MB231, MDA-MB468, T47D and BT20 also exhibited increased FOXM1 levels when compared to benign mammary cell lines (HMEC, MCF10A and MCF12A). Interestingly upregulation of FOXM1 was highly abundant in the breast cancer cell line MDAMB231, a cell line which was shown to be strongly metastatic in nude mouse models [24]. This implicates a possible association between FOXM1 upregulation and enhanced proliferation and invasiveness of cancer cells.

Upregulation of FOXM1 mRNA in breast tumors could be confirmed on protein level when analysing the immunohistochemistry results from a tissue microarray. $87 \%$ of breast carcinomas were shown to exhibit nuclear FOXM1 staining, compared to a percentage of $41 \%$ of normal breast tissue specimens showing nuclear FOXM1 expression. Thus FOXM1 was shown to be upregulated on both protein and mRNA level. The median expression level in breast tumour tissue showed an IRS of 3 while the median IRS of normal tissue was 0 . We next correlated nuclear FOXM1 expression with patients' survival data. Patients with nuclear FOXM1 expression showed a tendency towards unfavourable prognosis in overall survival analysis $(P=0.110)$. These data have to be confirmed in a prospective multi-centre trial including treatment information on FOXM1 positive and negative patients before FOXM1 overexpression in breast cancer can be considered as an established prognostic marker potentially useful for stratification of patient treatment.

This is the first study showing a significant association between nuclear FOXM1 expression and abundant expression of HER2 in breast cancer $(P=0.045)$. In a previous work of Yang et al. [25] FOXO4, another member of the Fox family, was found to inhibit HER2-activated cell growth by mediating p 27 transcription. Therefore FOXO4 was discussed as a novel anticancer agent in HER2-overexpressing cancers. It may be concluded that FOXM1 and FOXO4 have opposite effects on HER2 gene expression. The human epidermal growth factor receptor 2 (HER2) gene is localised on chromosome $17 \mathrm{q}$. It encodes a transmembrane tyrosine kinase receptor protein that is a member of the epidermal growth factor receptor (EGFR)/HER family [26]. HER2 gene amplification is found in 10-34\% of invasive breast tumours and is regarded as an important prognostic marker indicating poor patient survival [27]. Thus determination of the HER2 status is a very important step in clinical routine to analyse the right therapeutic strategy. Intriguingly, HER2-positive breast carci- 


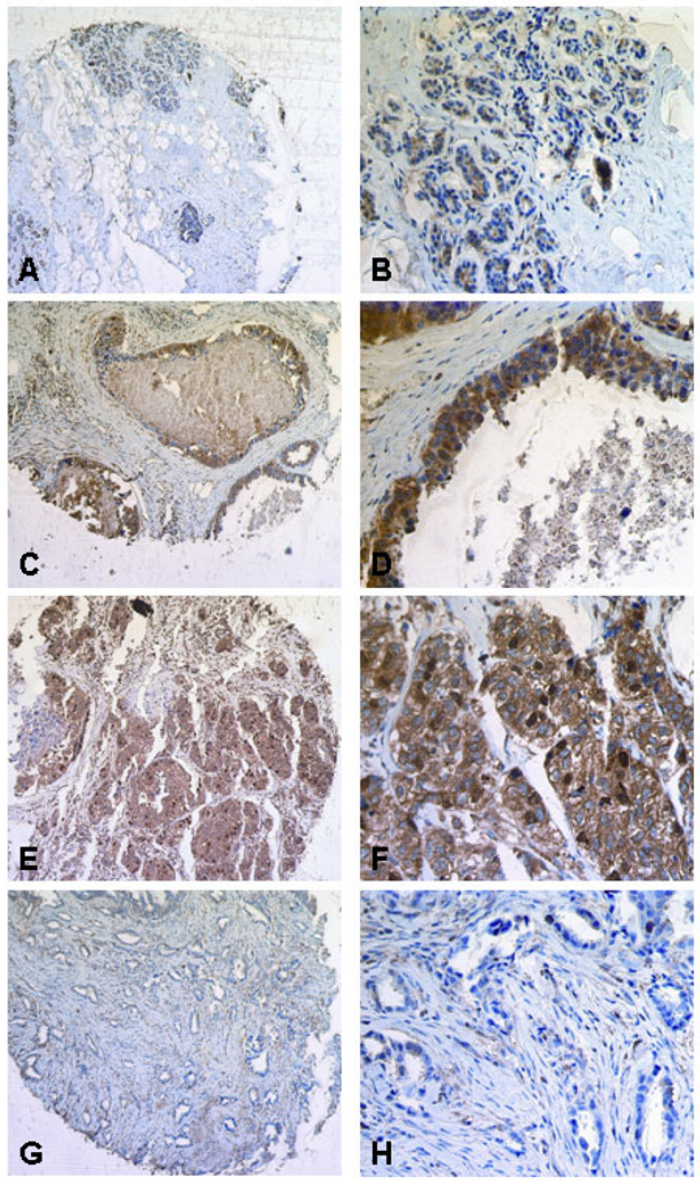

Figure 3

Immunohistochemical expression of FOXMI in normal breast tissue as well as in non-invasive and invasive breast tumours using a tissue microarray. (A, B) Normal breast tissue is detected with very weak FOXMI expression in the nucleus (IRS = I) and weak FOXMI expression in the cytoplasm (IRS = 4). (C, D) In ductal carcinoma in situ of high grade type nuclear FOXMI expression is a little more intense (IRS = 2) than in normal breast tissue whereas the cytoplasmic FOXMI expression is strong (IRS = 9). (E, F) In invasive breast carcinoma FOXMI expression was often stronger in the nucleus (IRS $=3$ ) as well as in the cytoplasm (IRS = I2) compared with normal breast tissue and ductal carcinoma in situ. (G, H) In tubular breast carcinoma, a rare variant of invasive breast carcinoma with a more favourable prognosis than invasive ductal breast carcinoma, nuclear and cytoplasmic FOXMI expression (each IRS $=3$ ) was weaker than in most invasive ductal breast carcinomas and stronger than in most normal breast tissues. Magnifications: A, C, E, G: I00x; B, D, F, H: 400x.

nomas are often associated with negative oestrogen and progesterone receptor status [28]. So these breast carcinomas will not respond to treatment regimens solely based on anti-hormones. For this reason in a fraction of HER2positive breast tumours a therapy with HER2 antibodies

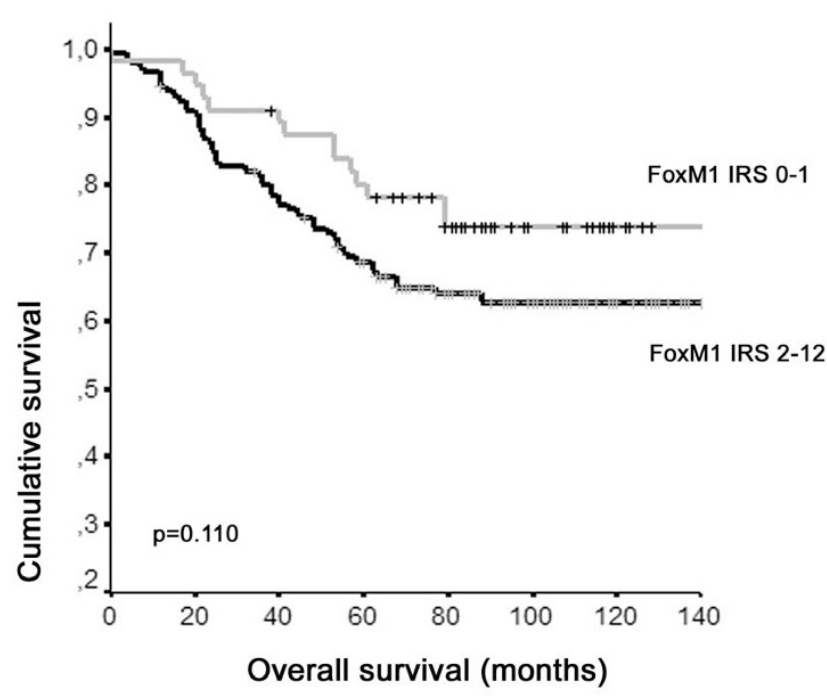

\section{Figure 4}

Breast cancer patients expressing nuclear FOXMI show a tendency towards unfavourable prognosis. Univariate Kaplan-Meier analysis was performed on basis of expression results from a tissue microarray. Patients with weak or absent nuclear FOXMI expression (IRS $=0-1$ ) displayed improved overall survival estimation (upper graph) as compared to patients with strong nuclear FOXMI expression (lower graph). Level of significance was only marginal $(\mathrm{P}=$ 0.I I 0; univariate log-rank analysis). IRS=Immunoreactive score according to Remmele et al. [23]. Crosses indicate censored patients.

(Trastuzumab, Herceptin ${ }^{\circledast}$ ) is applied. Nevertheless, most of the patients develop resistance to Herceptin ${ }^{\circledR}$ during therapy [28]. Analyses of other potential target molecules in signalling pathways of malignant mammary cells are of great interest and may offer alternative treatment options for patients with Herceptin ${ }^{\circledast}$ resistance. FOXM1 may be such a candidate molecule. Recently, FOXM1 inhibitors were discussed as new anticancer therapeutics $[18,19]$. Gusarova et al. [18] showed that inhibition of FOXM1 function by a cell-penetrating ARF (26-44) peptide lead to reduced tumour cell proliferation and angiogenesis in hepatocellular carcinoma. These studies were based on a mouse model. The apoptotic effect was also shown in human hepatoma cell lines. This inhibitory effect on FOXM1 has not been analysed for human breast cancer so far. Further functional studies including DNA binding studies are underway to analyse the interaction between FOXM1 and HER2, especially whether FOXM1 directly activates the HER2 (c-erbB-2) promoter. Recent studies show that FOXM1 protein might affect the transcription of oestrogen receptor alpha by binding to its promoter in vitro [10]. However, in our study we could not detect a significant correlation between FOXM1 expression and oestrogen or progesterone receptor status in human breast 
Table I: Clinicopathological and immunohistochemical parameters in relation to nuclear FOXMI immunoreactivity

\begin{tabular}{|c|c|c|c|c|c|}
\hline \multirow[t]{2}{*}{ Variable } & \multirow[t]{2}{*}{ Categorisation } & \multicolumn{4}{|c|}{ FOXMI immunoreactivity } \\
\hline & & n analysable & negative $^{b}$ & positive $^{b}$ & $\mathbf{p}^{c}$ \\
\hline \multicolumn{6}{|c|}{ Clinicopathological data: } \\
\hline \multicolumn{6}{|c|}{ Tumour stage $\mathrm{e}^{\mathrm{a}}$} \\
\hline & $\mathrm{pTI}$ & 61 & 18 & 43 & 0.339 \\
\hline & $\mathrm{pT} 2$ & 96 & 27 & 69 & \\
\hline & PT3 & 14 & 1 & 13 & \\
\hline & $\mathrm{pT} 4$ & 28 & 9 & 19 & \\
\hline \multicolumn{6}{|c|}{ Lymph node status ${ }^{\mathrm{a}}$} \\
\hline & pNO & 55 & 28 & 61 & 0.425 \\
\hline & $\mathrm{pNI}-3$ & 139 & 27 & 78 & \\
\hline \multicolumn{6}{|c|}{ Histological grade } \\
\hline & GI & 22 & 10 & 12 & 0.146 \\
\hline & $\mathrm{G} 2$ & 90 & 25 & 65 & \\
\hline & G3 & 87 & 21 & 66 & \\
\hline \multicolumn{6}{|c|}{ Multifocality } \\
\hline & unifocal tumour & 174 & 48 & 126 & 0.820 \\
\hline & multifocal tumour & 27 & 8 & 19 & \\
\hline \multicolumn{6}{|c|}{ Histological type } \\
\hline & ductal & 165 & 48 & 117 & 0.133 \\
\hline & lobular & 15 & I & 14 & \\
\hline & other & 18 & 6 & 12 & \\
\hline \multicolumn{6}{|c|}{$\begin{array}{l}\text { Immunohistochemistry (IHC): } \\
\text { Oestrogen receptor status }\end{array}$} \\
\hline & negative & 57 & 9 & 48 & 0.085 \\
\hline & positive & 103 & 29 & 74 & \\
\hline \multicolumn{6}{|c|}{ Progesterone receptor status } \\
\hline & negative & 115 & 27 & 88 & 0.702 \\
\hline & positive & 53 & 14 & 39 & \\
\hline \multicolumn{6}{|c|}{ HER2 status } \\
\hline & weak $(0-2+)$ & 154 & 45 & 109 & 0.045 \\
\hline & strong $(3+)$ & 18 & 1 & 17 & \\
\hline
\end{tabular}

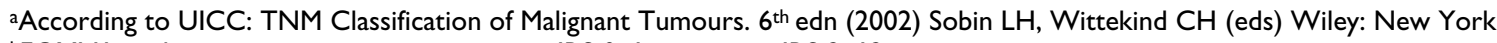

bFOXMI nuclear immunoreactivity: negative $=$ IRS 0-I, positive $=$ IRS 2-12

cFisher's exact test (two-sided), bold face representing significant data $(P<0.05)$

cancer. This might be related to the fact that previous studies were based on in vitro experiments using only breast carcinoma cell lines while our study analysed primary human cancer tissue. Considering the oestrogen receptor status we could in fact see a tendency towards negative correlation with nuclear FOXM1 expression $(P=0.085)$. As HER2-positive breast carcinomas are often associated with negative oestrogen and progesterone receptor status [28] these findings are in concordance with the results from our immunohistochemistry data.

Taken together, our analyses showed FOXM1 overexpression in human breast carcinoma relative to normal breast tissue on RNA and protein level indicating that FOXM1 may represent a novel oncogene in human breast cancer development. Interestingly, we could find a positive correlation between FOXM1 expression and HER2 status pointing to the potential role of FOXM1 as a new drug target in HER2 resistant breast tumour. Further studies are underway to analyse the interaction between FOXM1 and
HER2, especially whether FOXM1 directly activates the HER2 promoter and thus inevitably leads to HER2 overexpression.

\section{Conclusion}

FOXM1 may represent a novel breast tumour marker with prognostic significance that could be included into multimarker panels for breast cancer detection and treatment. Interestingly, we found a positive correlation between FOXM1 expression and HER2 status, additionally pointing to a potential role of FOXM1 as a new drug target in HER2 resistant breast tumour, as FOXM1 inhibitors for cancer treatment were recently described. Further studies are underway to analyse the potential interaction between FOXM1 and HER2, especially whether FOXM1 directly activates the HER2 promoter.

\section{Abbreviations}

FOXM1: Forkhead transcription factor; ER: Oestrogen receptor; ERS1: Oestrogen receptor gene 1; PR: Progester- 
Table 2: Univariate analysis of factors regarding overall survival (OS) and recurrence-free survival (RFS)

\begin{tabular}{|c|c|c|c|c|c|c|c|}
\hline \multirow[t]{2}{*}{ Variable } & \multirow[t]{2}{*}{ Categorisation } & \multicolumn{3}{|c|}{ Tumour-related death (OS) } & \multicolumn{3}{|c|}{ Tumour recurrence (RFS) } \\
\hline & & $\mathbf{n}$ & events & $\mathbf{p}^{c}$ & $\mathbf{n}$ & events & $\mathbf{p}^{\mathbf{c}}$ \\
\hline \multicolumn{8}{|c|}{ Clinicopathological data: } \\
\hline \multicolumn{8}{|c|}{ Tumour stage ${ }^{\mathrm{a}}$} \\
\hline & PTI & 61 & 11 & 0.001 & 59 & 14 & $<0.0001$ \\
\hline & PT2 & 96 & 34 & & 93 & 43 & \\
\hline & PT3 & 14 & 5 & & 13 & 7 & \\
\hline & PT4 & 28 & 17 & & 26 & 18 & \\
\hline \multicolumn{8}{|c|}{ Lymph node status ${ }^{\mathrm{a}}$} \\
\hline & pNo & 89 & 15 & $<0.0001$ & 87 & 17 & $<0.0001$ \\
\hline & $\mathrm{pNI}-3$ & 105 & 46 & & 102 & 60 & \\
\hline \multicolumn{8}{|c|}{ Histological grade } \\
\hline & GI & 22 & 5 & 0.003 & 21 & 6 & 0.001 \\
\hline & $\mathrm{G} 2$ & 90 & 23 & & 86 & 29 & \\
\hline & G3 & 87 & 39 & & 85 & 46 & \\
\hline \multicolumn{8}{|c|}{ Multifocality } \\
\hline & unifocal tumour & 174 & 55 & 0.165 & 168 & 70 & 0.348 \\
\hline & multifocal tumour & 27 & 12 & & 25 & 12 & \\
\hline \multicolumn{8}{|c|}{ Histological type } \\
\hline & ductal & 165 & 53 & 0.333 & 162 & 70 & 0.494 \\
\hline & lobular & 15 & 8 & & 13 & 6 & \\
\hline & other & 18 & 6 & & 16 & 5 & \\
\hline \multicolumn{8}{|c|}{ Immunohistochemistry (IHC): } \\
\hline \multicolumn{8}{|c|}{ Oestrogen receptor status } \\
\hline & negative & 57 & 24 & 0.027 & 57 & 29 & 0.057 \\
\hline & positive & 103 & 27 & & 99 & 33 & \\
\hline \multicolumn{8}{|c|}{ Progesterone receptor status } \\
\hline & negative & 115 & 49 & 0.001 & 109 & 52 & 0.015 \\
\hline & positive & 53 & 8 & & 53 & 14 & \\
\hline \multicolumn{8}{|l|}{ HER2 IHC } \\
\hline & weak $(0-2+)$ & 142 & 42 & 0.055 & 135 & 53 & 0.120 \\
\hline & strong $(3+)$ & 31 & 14 & & 31 & 16 & \\
\hline \multicolumn{8}{|l|}{ FOXMIb } \\
\hline & negative (IRS 0-I) & 56 & 14 & 0.110 & 54 & 23 & 0.581 \\
\hline & positive (IRS 2-12) & 146 & 53 & & 140 & 59 & \\
\hline
\end{tabular}

aAccording to UICC: TNM Classification of Malignant Tumours. $6^{\text {th }}$ edn (2002) Sobin LH, Wittekind CH (eds) Wiley: New York bFOXMI nuclear immunoreactivity: negative = IRS 0-I, positive $=$ IRS 2-I2

cLog-rank test (two-sided), bold face representing significant data $(P<0.05)$

one receptor; GAPDH: Glyeraldehyde-3-phosphate dehydrogenase; H\&E: hematoxylin and eosin; FISH: fluorescent in situ hybridisation; ATCC: American Type Culture Collection.

\section{Competing interests}

The author(s) declare that they have no competing interests.

\section{Authors' contributions}

NB: participated in design of the study, data analysis, data interpretation, establishment and evaluation of the immunohistochemistry and drafted the manuscript; AtH: carried out the immunohistochemical studies, and criti- cally revised the manuscript; JV: supported with expertise in molecular biology techniques and in data interpretation and critically revised the manuscript; PJW: supported in data interpretation and critically revised the manuscript; JLF: supported in establishment of the immunohistochemistry, data interpretation and critically revised the manuscript; RK: participated in design and coordination of the study, and critically revised the manuscript; ED conceived the study, participated in study design and coordination, molecular and data analysis, data interpretation and drafting of the manuscript.

All authors read and approved the final manuscript. 


\section{Acknowledgements}

The technical assistance of Inge Losen and Sonja von Serényi is greatly appreciated. The study was supported by the German Ministry for Education and Research (BMBF) as a part of the German Human Genome Project (DHGP) to Edgar Dahl and by a grant (START program) of the Faculty of Medicine, RWTH Aachen to Nuran Bektas.

\section{References}

I. Kaestner $\mathrm{KH}$, Knochel W, Martinez DE: Unified nomenclature for the winged helix/forkhead transcription factors. Genes Dev 2000, I 4(2): | $42-6$.

2. Lehmann OJ, Sowden JC, Carlsson P, Jordan T, Bhattacharya SS: Fox's in development and disease. Trends Genet 2003, I 9(6):339-44.

3. Korver $\mathrm{W}$, Roose J, Clevers $\mathrm{H}$ : The winged-helix transcription factor Trident is expressed in cycling cells. Nucleic Acids Res 1997, 25(9): I715-9.

4. Yao KM, Sha M, Lu Z, Wong GG: Molecular analysis of a novel winged helix protein, WIN. Expression pattern, DNA binding property, and alternative splicing within the DNA binding domain. J Biol Chem 1997, 272(32): I9827-36.

5. Korver W, Schilham MW, Moerer P, van den Hoff MJ, Dam K, Lamers $\mathrm{WH}$, Medema $\mathrm{RH}$, Clevers $\mathrm{H}$ : Uncoupling of $\mathbf{S}$ phase and mitosis in cardiomyocytes and hepatocytes lacking the winged-helix transcription factor Trident. Curr Bio 1998, 8(24): I 327-30.

6. Leung TW, Lin SS, Tsang AC, Tong CS, Ching IC, Leung WY, Gimlich $R$, Wong GG, Yao KM: Over-expression of FOXMI stimulates cyclin B I expression. FEBS Lett 200I, 507(I):59-66.

7. Wonsey DR, Follettie MT: Loss of the Forhhead Transcription Factor FOXMI Causes Centrosome Amplification and Mitotic Catastrophe. Cancer Res 2005, 65( I 2):5I8I-5I89.

8. Okabe H, Satoh S, Kato T, Kitahara O, Yanagawa R, Yamaoka Y, Tsunoda T, Furukawa $Y$, Nakamura $Y$ : Genome-wide analysis of gene expression in human hepatocellular carcinomas using cDNA microarray: identification of genes involved in viral carcinogenesis and tumor progression. Cancer Res 200 I, 6 I (5):2 I 29-37.

9. Castedo M, Perfettini JL, Roumier T, Andreau K, Medema R, Kroemer $\mathrm{G}$ : Cell death by mitotic catastrophe: a molecular definition. Oncogene 2004, 23( 16):2825-37.

10. Madureira PA, Varshochi R, Constantinidou D, Francis RE, Coombes $\mathrm{RC}$, Yao KM, Lam EW: The Forkhead box MI protein regulates the transcription of the estrogen receptor alpha in breast cancer cells. J Biol Chem 2006, 28 I(35):25I67-76.

II. Khan SA, Rogers MA, Khurana KK, Meguid MM, Numann PJ: Estrogen receptor expression in benign breast epithelium and breast cancer risk. I Natl Cancer Inst I998, 90(I):37-42.

12. Ricketts D, Turnbull L, Ryall G, Bakhshi R, Rawson NS, Gazet JC, Nolan C, Coombes RC: Estrogen and progesterone receptors in the normal female breast. Cancer Res I991, 51 (7):1817-22.

13. Moy B, Goss PE: Estrogen receptor pathway: resistance to endocrine therapy and new therapeutic approaches. Clin Cancer Res 2006, I 2(16):4790-3.

14. Coombes RC, Powles TJ, Berger U, Wilson P, McClelland RA, Gazet JC, Trott PA, Ford HT: Prediction of endocrine response in breast cancer by immunocytochemical detection of oestrogen receptor in fine-needle aspirates. Lancet 1987, 2(856I):70I-3.

15. Taylor RE, Powles TJ, Humphreys J, Bettelheim R, Dowsett M, Casey A], Neville AM, Coombes RC: Effects of endocrine therapy on steroid-receptor content of breast cancer. Br J Cancer 1982, 45(I):80-5.

16. Dahl E, Sadr-Nabavi A, Klopocki E, Betz B, Grube S, Kreutzfeld R, Himmelfarb M, Gelling S, Klaman I, Hinzmann B, Kristiansen G, Grützmann R, Kuner R, Petschke B, Rhiem K, Wiechen K, Sers C, Wiestler O, Schneider A, Höfler H, Nährig J, Dietel M, Schäfer R, Rosenthal A, Schmutzler R, Dürst M, Meindl A, Niederacher D: Systematic identification and molecular characterization of genes differentially expressed in breast and ovarian cancer. J Pathol 2005, 205(I):2I-8.

17. Dahl E, Kristiansen G, Gottlob K, Klaman I, Ebner E, Hinzmann B, Hermann K, Pilarsky C, Durst M, Klinkhammer-Schalke M, Blaszyk H, Knuechel R, Hartmann A, Rosenthal A, Wild PJ: Molecular profiling of laser-microdissected matched tumor and normal breast tissue identifies karyopherin alpha2 as a potential novel prognostic marker in breast cancer. Clin Cancer Res 2006. I 2(I3):3950-60.

18. Gusarova GA, Wang IC, Major ML, Kalinichenko VV, Ackerson T, Petrovic $\mathrm{V}$, Costa $\mathrm{RH}$ : A cell-penetrating ARF peptide inhibitor of FOXMI in mouse hepatocellular carcinoma treatment. J Clin Invest 2007, I I 7( I):99- I I I.

19. Radhakrishnan SK, Bhat UG, Hughes DE, Wang IC, Costa RH, Gartel $A L$ : Identification of a chemical inhibitor of the oncogenic transcription factor forkhead box ml. Cancer Res 2006, 66(19):973|-5.

20. Elston CW, Ellis IO: Pathological prognostic factors inbreast cancer. I. The value of histological grade in breast cancer: experience from a large study with long-term follow-up. Histopathology 1991, 19(5):403-10.

21. Zafrakas M, Chorovicer M, Klaman I, Kristiansen G, Wild PJ, Heindrichs U, Knüchel R, Dahl E: Systematic characterisation of GABRP expression in sporadic breast cancer and normal breast tissue. Int J Cancer 2006, I I 8(6): |453-9.

22. Veeck J, Niederacher D, An H, Klopocki E, Wiesmann F, Betz B, Galm O, Camara O, Durst M, Kristiansen G, Huszka C, Knuchel R, Dahl E: Aberrant methylation of the Wnt antagonist SFRPI in breast cancer is associated with unfavourable prognosis. Oncogene 2006, 25(24):3479-88.

23. Remmele W, Stegner HE: Recommendation for uniform definition of an immunoreactive score (IRS) for immunohistochemical estrogen receptor detection (ER-ICA) in breast cancer tissue. Pathologe 1987, 8(3): | 38-40.

24. Gallagher SM, Castorino J], Wang D, Philp NJ: Monocarboxylate Transporter 4 Regulates Maturation and Trafficking of CDI47 to the Plasma Membrane in the Metastatic Breast Cancer Cell Line MDA-MB-23 I. Cancer Res 2007, 67(9):4I82-9.

25. Yang $H$, Zhao $R$, Yang HY, Lee MH: Constitutively active FOXO4 inhibits Akt activity, regulates p27 Kip I stability, and suppresses HER2-mediated tumorigenicity. Oncogene 2005 , 24(I I): 1924-35.

26. Stern DF, Heffernan PA, Weinberg RA: p I 85, a product of the neu proto-oncogene, is a receptorlike protein associated with tyrosine kinase activity. Mol Cell Biol 1986, 6(5): I729-40.

27. Ross JS, Fletcher JA, Linette GP, Stec J, Clark E, Ayers M, Symmans WF, Pusztai L, Bloom KJ: The Her-2/neu gene and protein in breast cancer 2003: biomarker and target of therapy. Oncologist 2003, 8(4):307-25.

28. Nahta R, Esteva FJ: HER2 therapy. Molecular mechanisms of trastuzumab resistance. Breast Cancer Res 2006, 8(6):2I5.

\section{Pre-publication history}

The pre-publication history for this paper can be accessed here:

http://www.biomedcentral.com/1471-2407/8/42/prepub

Publish with Bio Med Central and every scientist can read your work free of charge

"BioMed Central will be the most significant development for disseminating the results of biomedical research in our lifetime. "

Sir Paul Nurse, Cancer Research UK

Your research papers will be:

- available free of charge to the entire biomedical community

- peer reviewed and published immediately upon acceptance

- cited in PubMed and archived on PubMed Central

- yours - you keep the copyright

Submit your manuscript here:

http://www.biomedcentral.com/info/publishing_adv.asp
BioMedcentral 